\title{
The effect of group logo therapy on the burden of hemodialysis patients' caregivers
} \author{
Leila Kasirlou ${ }^{5}$ \\ ${ }^{1}$ Social Determinants of Health Research Center, Qazvin University of Medical Sciences, Qazvin, Iran \\ ${ }^{2}$ Student Research Committee, Qazvin University of Medical Sciences, Qazvin, Iran \\ ${ }^{3}$ School of Nursing and Midwifery, Qazvin University of Medical Science, Qazvin, Iran \\ ${ }^{4}$ Student Research Committee, Mashhad University of Medical Sciences, Mashhad, Iran \\ ${ }^{5}$ Student Research Committee, Qazvin University of Medical Sciences, Qazvin, Iran
}

Seyedeh Zahra Hosseinigolafshani ${ }^{{ }^{*}}{ }^{\circledR}$, Sorayah Taheri ${ }^{2^{\circledR}}$, Maryam Mafi ${ }^{\circledR}$, Mohamad Hossein Mafi ${ }^{\circledR}$,

\section{A R T I C L E I N F O \\ Article Type: \\ Original \\ Article History: \\ Received: 30 April 2020 \\ Accepted: 2 July 2020 \\ Published online: 22 July 2020}

Keywords:

Group logo therapy

Caregiver Burden

Hemodialysis

End-stage renal disease

Chronic kidney disease

Renal replacement therapy

\begin{abstract}
A B S T R A C T
Introduction: The relationship between caregivers and patients plays a vital role in providing effective care.

Objectives: The aim of this study was to investigate the effect of group logo therapy on the burden of hemodialysis patients' caregivers.

Patients and Methods: The present research was a quasi-experimental study with pretestposttest design. The study population was all caregivers of hemodialysis patients in Qazvin. The sample of this study consisted of 100 caregivers (50 participants in the intervention group and 50 participants in the control group) who were selected according to the inclusion criteria and then randomly allocated in two groups. After the initial evaluation of burden in both groups, 10 sessions, (90 minutes for each session) logo therapy was conducted for intervention group. Immediately after the end of the course and one month later, the intensity of caregiver burden in both groups was measured. The data collection tools were demographic questionnaires for the patient and caregiver and the Zarit Burden Interview.

Results: In this study we found, the intervention group with a mean score of $44.6 \pm 7.4$ and the control group with a mean score of $44.8 \pm 5.38$ experienced severe burden. Regarding the effect of logo therapy on caregiver burden, the results showed that the mean score of burden before the intervention was $44.6 \pm 7.4$ and immediately after the intervention and one month later were $37.2 \pm 12.6$ and $2.14 \pm 6.34$, respectively $(P<0.001)$.

Conclusion: The findings showed the positive effect of group logo therapy on reducing the burden of hemodialysis patients' caregivers. Considering the high level of caregiver burden, it appears that the application of logo therapy in educational programs for dialysis centers is necessary to reduce the caregiver burden and improve the quality of life.
\end{abstract}

Implication for health policy/practice/research/medical education:

To investigate the effect of group logo therapy on the burden of hemodialysis patients' caregivers, we conducted a study on 100 caregivers (50 participants in the intervention group and 50 participants in the control group). We found that the application of group logo therapy can significantly reduce the burden of caregivers of hemodialysis patients.

Please cite this paper as: Hosseinigolafshani SZ, Taheri S, Mafi M, Mafi MH, Kasirlou L. The effect of group logo therapy on the burden of hemodialysis patients' caregivers. J Renal Inj Prev. 2020; 9(4): e33. doi: 10.34172/jrip.2020.33.

\section{Introduction}

The end-stage renal disease is a condition of chronic kidney disease that results in death in case of absence of renal replacement therapy (1). Throughout the world, by the end of 2016, the number of patients with the endstage renal disease was approximately 3730000 (2). Renal replacement therapy includes hemodialysis, peritoneal dialysis and transplantation. Shortage of kidneys for transplantation makes hemodialysis the main focus of renal replacement therapy (3). By the end of 2016, 2648000 people were under hemodialysis around the world (2). Hemodialysis causes patients to experience a 
wide range of physical, psychological, economic and social problems (4). These patients are physically and mentally disabled to do their daily care and need caregivers to take care of them (5).

A caregiver refers to a person who helps a disabled person to do daily care. Caregivers can have a family relationship with the patient or can be their friends or neighbors who take care of disabled people without being paid (6). Caregivers play a vital role in supporting patients and should do supportive and caring activities at home or healthcare facilities, which can have an impact on patients' physical and mental health in varying degrees (7). Longterm care is an erosion activity that gradually causes stress and depression symptoms in the caregiver, therefore the caregiver sometimes becomes extremely tired and burnout (8). Stress related to care affects caregivers' lives and health in varying degrees (9). For instance, caregivers of hemodialysis patients experience some degree of disappointment due to the uncertainty of their patients' future (8). Studies show that, in addition to mental health, caregivers' physical health is also affected by their work burden. This causes caregivers to be physically ill and results in disorders such as hypertension, anxiety, depression and early aging due to caregiver burden (9).

Caregiver burden is a form of physical, emotional and mental pressure that results from the long-term care of a person. Caregiver burden affects caregivers' physical or emotional health, social life, or financial status (10). Evidence suggests that caregiver burden can be a strong predictor of anxiety, depression and decreased quality of life in caregivers (11). Therefore many caregivers report loneliness, depression and poor physical and mental health, followed by work burnout and poor quality of care. These are often due to prioritizing patients' physical, psychological and social needs over caregivers' needs (4, 12). However less attention is often paid to caregivers and the focus is mostly on patients. This problem exacerbates disorders in different dimensions of caregivers' health, especially their mental health (11). Generally, quality of life of caregivers' is significantly related to their health and caregiver burden. Moreover, the relationship between caregivers and patients plays a vital role in providing care. Hence, providing strategies to pay more attention and assess the level of caregiver burden among caregivers appears to be necessary, which leads to improvements in different dimensions of caregivers' health and provision of effective care (13).

One of the common strategies for restoring and improving health, especially the psychological aspect, is logo therapy that reduces individuals' frustration and increases their hopes (14). This approach is an active treatment that seeks to help the patient, especially in the critical stages of life (15). Frankl as the theorist of this approach believes that finding a meaning is considered as the primary human motivation, since this treatment is a type of adaptive act (16). In fact, logo therapy focuses on the meaning and believes that the attempt to find meaning is one of the most powerful motivator factors (17). One of the main effects of logo therapy is the creation of hope in a person, which is a positive motivation that focuses on a clear goal for life (18). In fact, logo therapy seeks to deepen lives of individuals through giving meaning to them (19). Finding the meaning in life is a difficult process and it happens when one has a strong motivation to do that (20). Trying to find meaning in life is the most basic motivation of the individual and turns hopelessness into hope (21).

\section{Objectives}

The results of several studies showed a positive and significant relationship between meaning in life, quality of life and satisfaction with optimism. Similarly, having the meaning in life has a negative relationship with anxiety, depression and distress (20). Despite high caregiver burden, no study has been conducted on the effectiveness of logo therapy on caregivers of hemodialysis patients. Therefore, the present study was designed with the aim of answering this question "is logo therapy effective in reducing burden of hemodialysis patients' caregivers?”

\section{Patients and Methods}

Study protocol

The present study was a quasi-experimental study with pretest-posttest design. The study population was all caregivers of hemodialysis patients at the Bouali hospital in Qazvin. Based on previous studies (22) and the following formula, the sample size for this study was estimated to be 41 subjects. By considering a 20\% attrition rate, a total of 50 participants in each group (intervention and control) were enrolled in the study.

$$
n=\frac{\left(\mathrm{Z}_{1-\frac{\alpha}{2}}+Z_{1-} B\right)^{2}\left({\sigma_{1}}^{2}+\sigma_{2}{ }^{2}\right)}{\left(\mu_{1}-\mu_{2}\right)} \cong 41.6
$$

The subjects were selected according to the inclusion and exclusion criteria. First, the patients and their caregivers were asked to participate in the study. To enter the study, the patients should have "full" to "very low" dependence on the caregivers. This was evaluated by asking the patients to respond to two questions. Those who answered "yes" to the first question which was "I can do my works very well" or the second question "I do not need a caregiver at all" were excluded.

The inclusion criteria for the caregivers were 1) having a family relationship with the patient; 2) being willing to participate in the study; 3) being responsible for direct care of the patient for at least six months; 4) being at least 18 years; 5) not receiving any payment for taking care of the patient; 6) not having any psychological illness or using psychotropic drugs; 7) not being responsible for the care of another person; and 8) being able to write and read 
Persian. The exclusion criteria for the caregivers included; being absent in more than two sessions of logo therapy and; being unwilling to participate in the study.

In the first step, after identifying potential samples for participation in the study, caregiver burden was measured as a pre-test design using the Zarit Burden Interview. Individuals who obtained relatively high level of caregiver burden were selected and randomly allocated into the intervention $(n=50)$ or control $(n=50)$ group. Logo therapy sessions were held for the intervention group in 10 sessions of 120 minutes weekly by the responsibility of a clinical psychologist and a critical care nursing student. The content provided in each session is as follows;

Session 1; determining the goals and rules of the group session, introducing the members to each other, presenting the charter of the group and obtaining agreement on the time of each session.

Session 2; defining freedom as a human right, finding meaning at the work, love and leisure time.

Session 3; debating on accepting responsibility in designing and pursuing goals and expectations.

Session 4; addressing anxiety as an integral part of being.

Homework; attempting to reduce the amount of anxiety by restoring life and decreasing our choices.

Session 5; finding meaning through creation of values and discussing about the relationship between the nature of disease and life expectancy with meaning.

Homework; finding meaning in suffering.

Session 6; finding meaning through creation of creative values and also through experiencing values, criteria, hope, desires and dreams in life.

Session 7; finding meaning through empirical values and attitudes and finding meaning in sickness, death and freedom (acceptance of non-modifiable dimensions of life).

Session 8; accepting the responsibility of change, selfsupport and trust, being confident and having hope for the future and paying attention to values and desires in life.

Session 9; encouraging members to emotionally support each other, completing unfinished sentences like "I feel uncomfortable when..."

Session 10; training on maintenance and resilience skills, group discussion learning and how to consider them in life, summarizing the content of all the sessions and eventually taking post-tests.

To maintain the standards of logo therapy, the 50 participants in the intervention group were divided into two groups of 25 people by the opinion of the specialized consultant. Then, the logo therapy sessions for each group were held with the same content. In the control group, no logo therapy was carried out. However in order to observe ethical principles, the study content was given to them at the end of the study. Finally, 44 participants in the control group and 43 participants in the intervention group remained. To evaluate the effect of logo therapy, caregiver burden was measured as a post-test design at two time periods, immediately after the end of the sessions and one month later.

\section{Instruments}

In this study, two instruments were used:

1. Demographic questionnaires for the patient (13 items) and caregiver (17 items)

2. The Zarit Burden Interview.

The validity and reliability of the two demographic questionnaires were confirmed by the faculty members who were expert in critical care nursing.

The Zarit Burden Interview was developed by Zarit et al in 1998 to evaluate the level of caregiver burden (4). The instrument consists of 22 items focusing on personal, social, emotional and economic burden that were completed through interviews with the caregivers. The caregivers' response for each item was measured on a 5 -point Likert scale (never to always) which is scored from zero to four; never (0), rarely (1), sometimes (2), often (3) and always (4). Finally, the total scores of caregiver burden ranged from 0 to 88 . The final interpretation of the scores is as follows; the score of 0 to 20 demonstrates no or low levels of caregiver burden, and the score of 21 to 40 demonstrates moderate caregiver burden since the score of 41 to 88 demonstrates high levels of caregiver burden.

In the content validity of the instrument, all the items had a desirable CVI (content validity index) between 0.7 and 1 (4). Previous studies also determined the validity of the instrument to be desirable (22). The reliability of the instrument was 0.86 using Cronbach's alpha (4). Moreover, in other studies, the reliability was determined to be $77 \%$ (22) and 94\% (23) using the test-retest method (Figure 1).

\section{Ethical issues}

The study was in accordance with the Declaration of Helsinki and its later amendments. This study was approved by the ethics committee of Qazvin University of Medical Sciences (\#IR.QUMS.REC.1396.331). All the participants were informed about the study aims and procedures. Informed consent was obtained from all the patients and their caregivers.

\section{Statistical analysis}

Data were analyzed using descriptive (frequency, mean, standard deviation) and analytical tests (paired $t$ test, independent $t$ test, chi-square and ANOVA) in SPSS version 24. For determining normal distribution of data, Kolmogorov-Smirnov and Shapiro tests were used. The significance level was set as $P<0.05$.

\section{Results}

The present study was conducted to investigate the effect of group logo therapy on burden of hemodialysis patients' 


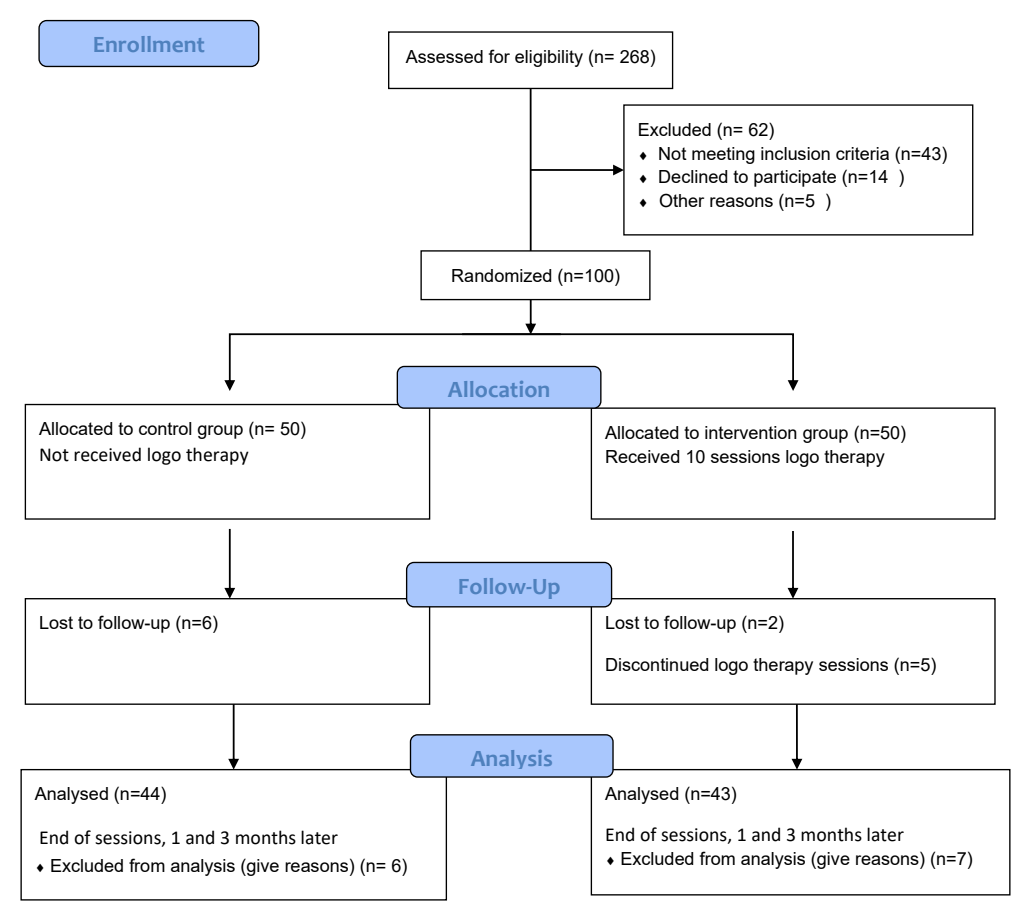

Figure 1. Flow diagram of the study (CONSORT).

caregivers. Statistical analysis was finally performed based on data obtained from 87 hemodialysis caregivers (44 caregivers in the control group and 43 caregivers in the intervention group). The mean and standard deviation of the caregivers' age was $45.2 \pm 14.8$ years. Moreover, the mean duration of patient care was $50.9 \pm 53.3$ months. Of all the caregivers, 52 of them (59.8\%) were female and 35 (40.2\%) were male. In terms of marital status, 18 (20.7\%) were single and $69(79.3 \%)$ were married. Most of the caregivers, 35 (40.2\%) were under the diploma and only $23(26.4 \%)$ had academic education and among them, six (6.9\%) caregivers had academic education related to the medicine.

In terms of the patients' demographic information, mean age and duration of hemodialysis were $65.2 \pm 13.9$ and $42.7 \pm 41.8$ years, respectively. Forty-eight (55.2\%) of the patients were female. Regarding the marital status, five $(5.7 \%)$ of them were single, $62(71.3 \%)$ were married and $20(23 \%)$ were widows (the spouse was dead). The majority of the patients $(n=44,50.6 \%)$ were illiterate and only $12(13.8 \%)$ had diplomas or higher degree. In terms of employment, 27 (31\%) of them were housewives, 22 (25.3\%) were unemployed, 17 (19.5\%) were self-employed and $21(24.1 \%)$ were retired. According to the results of the independent t-test and chi-square test, the demographics characteristics were similar in both groups (intervention and control) (Table 1).

\section{Comparison between groups}

This study showed that the mean score of caregiver burden in the intervention and control groups was $44.6 \pm 7.4$ and
$44.8 \pm 5.38$, respectively. Thus, the caregivers experienced severe burden. For determining normal distribution of the data related to caregiver burden, we used KolmogorovSmirnov and Shapiro tests. According to the results of these tests, the scores of caregiver burden had normal distribution in both groups.

According to the results, mean score of caregiver burden before study in the intervention and control group was $44.6 \pm 7.4$ and $44.8 \pm 5.3$, respectively, which was not statistically significant. Table 2 shows the result in more details.

The mean score of caregiver burden, immediately after logo therapy in the intervention and control groups was $37.2 \pm 12.66$ and $46.7 \pm 8.7$, respectively. According to the results of $t$ test, the difference between the groups was statistically significant $(P<0.05$; Table 2$)$.

The mean score of caregiver burden one month after logo therapy in the intervention and control groups was $34.6 \pm 14.2$ and $43.1 \pm 12.7$, respectively. According to t-test analysis, the difference between the groups was statistically significant $(P<0.05$; Table 2$)$.

\section{Comparison within groups}

For comparing two groups, we used repeated measure ANOVA test. According to t-test analysis, the decrease in mean score of caregiver burden before and immediately and also one month after logo therapy in the intervention group was statistically significant $(P<0.05)$. In the control group, there was not any significant change during these three times period (Table 2 and Figure 2). 
Table 1. The demographics information of the patients and their caregivers

\begin{tabular}{|c|c|c|c|c|}
\hline \multicolumn{2}{|c|}{ Personal information of the patients and caregivers } & \multirow{2}{*}{$\frac{\text { Intervention group }(\mathrm{n}=\mathbf{4 3})}{29(67.5)}$} & \multirow{2}{*}{$\frac{\text { Control group }(n=44)}{23(53.3)}$} & \multirow{3}{*}{$\begin{array}{c}P \text { value } \\
0.14^{*}\end{array}$} \\
\hline \multirow{2}{*}{ Gender (caregiver) } & Woman & & & \\
\hline & Man & $14(32.5)$ & $21(47.7)$ & \\
\hline \multirow{2}{*}{ Gender (patient) } & Woman & $21(48.8)$ & $27(56.2)$ & \multirow{2}{*}{$0.24^{*}$} \\
\hline & Man & $22(51.2)$ & $17(43.5)$ & \\
\hline \multirow{2}{*}{ Marital status (caregiver) } & Single & $10(23.3)$ & $8(18.2)$ & \multirow{2}{*}{$0.5^{*}$} \\
\hline & Married & $33(37.7)$ & $36(81.8)$ & \\
\hline \multirow{3}{*}{ Marital status (patient) } & Single & $1(12.3)$ & $4(9)$ & \multirow{3}{*}{$0.09 *$} \\
\hline & Married & $35(81.4)$ & $27(61.4)$ & \\
\hline & Widow & $7(16.3)$ & $13(29.6)$ & \\
\hline \multirow{4}{*}{ Education (caregiver) } & Illiterate & $3(7)$ & $4(9.1)$ & \multirow{4}{*}{$0.9^{*}$} \\
\hline & Under the Diploma & $18(41.8)$ & $17(38.6)$ & \\
\hline & Diploma or Higher & $11(25.6)$ & $11(25)$ & \\
\hline & Academic & $11(25.6)$ & $12(27.3)$ & \\
\hline \multirow{2}{*}{$\begin{array}{l}\text { Medical education } \\
\text { (caregiver) }\end{array}$} & Yes & $4(9.3)$ & $2(4.6)$ & \multirow{2}{*}{$0.43^{*}$} \\
\hline & No & $39(90.7)$ & $42(95.4)$ & \\
\hline \multirow{3}{*}{ Education (patient) } & Illiterate & $19(44.2)$ & $25(56.8)$ & \multirow{3}{*}{$0.4^{*}$} \\
\hline & Under the Diploma & $18(41.8)$ & $13(29.5)$ & \\
\hline & Diploma or Higher & $6(14)$ & $6(13.7)$ & \\
\hline \multicolumn{2}{|l|}{ Age (caregiver) } & $46.2 \pm 14.7$ & $44.1 \pm 14.9$ & $0.5^{* *}$ \\
\hline \multicolumn{2}{|l|}{ Age (patient) } & $65.5 \pm 10.8$ & $64.8 \pm 16.8$ & $0.84^{* *}$ \\
\hline \multicolumn{2}{|l|}{ Duration of care } & $9.11 \pm 2.55$ & $7.08 \pm 7.46$ & $0.46 * *$ \\
\hline
\end{tabular}

${ }^{*}$ Chi-square-test; ${ }^{* *}$ Independent $t$ test.

Table 2. Comparison of the mean score of caregiver burden before, immediately and one month after logo therapy in the both groups

\begin{tabular}{lccc}
\hline & & Caregiver Burden & \\
\cline { 2 - 3 } Group & Before intervention & After intervention & One month after intervention \\
& Mean \pm SD & Mean \pm SD & Mean \pm SD \\
\hline Intervention & $44.6 \pm 7.4$ & $37.2 \pm 12.6$ & $34.6 \pm 14.2$ \\
Control & $44.8 \pm 5.3$ & $46.7 \pm 8.7$ & $43.1 \pm 12.7$ \\
$P$ value** & $\mathrm{t}=0.14, P=0.8$ & $\mathrm{t}=4.2, P<0.001$ & $\mathrm{t}=2.8, P=0.005$ \\
\hline
\end{tabular}

${ }^{*}$ Repeated measure ANOVA; ${ }^{* *} t$ test

\section{Discussion}

In this study we found, mean score of caregiver burden in the intervention and control groups was $44.6 \pm 7.4$ and $44.8 \pm 5.38$, respectively, therefore, the caregivers experienced severe burden. Most of the previous studies also showed that caregivers of hemodialysis patients experience high levels of caregiver burden that is similar to the findings of the present study. In this regard, Cantekin et al reported that $86.9 \%$ of hemodialysis patients' caregivers experienced moderate to severe level of burden (24). The study of Alnazly et al among Jordanian caregivers showed that most of caregivers (76\%) experienced severe level of burden (25). However, Mobolaji et al reported that (48.3\%) of hemodialysis patients' caregivers in Nigeria experienced mild-to-moderate burden, (10.4\%) experienced severe burden while only (1.3\%) experienced very severe burden (26). Similarly, the result of the study by Nagarathnam et al showed, a higher percentage of caregivers (85\%) had mild to moderate burden (27). The contradictory results of these studies can be due to cultural differences and national values that require further studies with a deep qualitative approach.

In another study, Mollaoğlu et al examined the effects of an educational program related to home care on the caregiver burden of caregivers of hemodialysis patients. Results of their study showed that the mean score of caregiver burden was high among caregivers while those with low-education levels experienced more levels of burden (28).

Contrary to the results of the present study, the results of the study by Rioux et al showed low levels of burden among hemodialysis caregivers, which can be attributed to some factors, such as nocturnal dialysis at home, independency and the ability of most patients to self-care with highly educated caregivers (29). Studies have shown that caregivers of patients suffer greatly from various physical, mental, emotional, social and economical dimensions (26). Recent studies have also shown that home caregivers, 


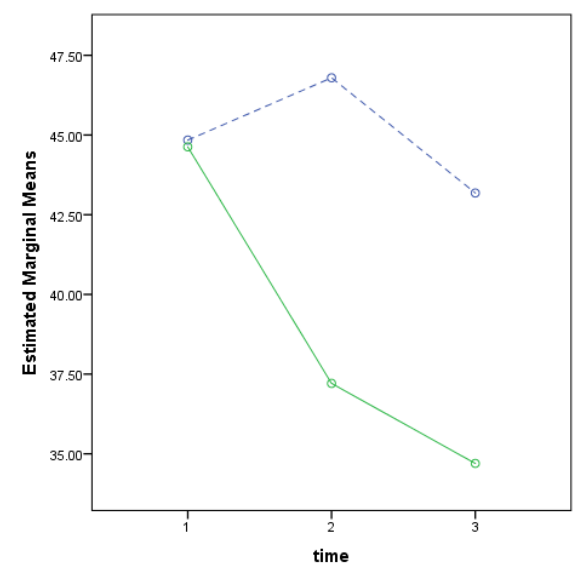

Figure 2. Comparison of caregivers burden, before, immediately after and one month later of group logo therapy.

in addition to physical problems, experience feelings of despair, guilty, anger, stress, depression and loneliness (29, 30). In line with this finding, the results of various studies showed that the pressure of taking care of chronic patients imposes multiple physical and psychological problems on caregivers, while the consequences of which can directly have an impact on reduction the quality of care $(4,12)$.

The results of our study on the effect of group logo therapy on caregiver burden showed that after the intervention, the score of caregiver burden in the intervention group with a mean score of $37.2 \pm 12.66$ was lower than of control group with the mean score of 46.7 \pm 8.7 while this reduction was statistically significant. The mean score of caregiver burden in the intervention group one month after the intervention was $34.6 \pm 14.2$, which showed a significant reduction compared to that in control group with a mean score of $43.1 \pm 12.7$.

Few studies were conducted about the effect of logo therapy on caregivers, especially caregivers of hemodialysis patients; however, recent studies have been conducted on the effect of group logo therapy on life expectancy, mental health, death-related anxiety, depression, quality of life in the elderly patients. Recently, the study of Kang (31) showed the positive effect of logo therapy on quality of life in cancer patients. Moreover, the study of ShinJeong et al (32) showed the positive effect of logo therapy on life expectancy and meaning of life in patients. In explaining of their results, it can be argued that in spite of disappointment, logo therapy helps patients and their caregivers not to focus on the missing and should be attempted to make the sense in life by finding the aim and motivation. Therefore, the efforts made from meaning, joy since disappointment make one feel success and hope (18).

Furthermore, caregivers of hemodialysis patients are also suffering from mental pressures such as dependency, fear of losing the patient and emotional reactions as much as financial, physical problems and social constraints (4). In this regard Morgan et al (17), James et al (33), Belasco et al (34) and Cohen et al (35) also showed that logo therapy was effective on spiritual wellbeing and quality of life and general health.

Logo therapy gives one, the opportunity to confront with underlying concerns and concepts of life such as life and death, hope and disappointment, communicating with others or isolation, having free choices, awareness and sense of responsibility towards oneself and others, selfexcellence and searching for meaning in a period of life close to death (36). In explaining this concept, it can be mentioned that logo therapy can help caregivers to overcome the internal turbulence of thinking about losing the patient and death and feel calm.

In fact, logo therapy helps caregivers of hemodialysis patients to make their potential capability to be stronger and turn the tragedy into a victory and thus they make self-progress in such a distressed situation. According to Frankl's perspective, such people define their lives by challenging themselves with inevitable obstacles of life. In fact, the meaning must be such that most difficult moments of life can be tolerated $(7,37)$. Moreover, due to passing and decay of human's life, logo therapy calls one to work and make efforts instead of being pessimist and feeling isolated, and states that what causes humans to experience failure is not their pain and undesirable nature, but the meaninglessness of life which is a disaster (38).

\section{Conclusion}

Our study showed the Frankl's theory of logo therapy; the application of group logo therapy can significantly reduce the burden of caregivers of hemodialysis patients. Considering the focus of the Iranian Ministry of Health policies on improving the quality of life of hemodialysis patients and their caregivers, group logo therapy can be utilized as a continued educational program in dialysis centers.

\section{Limitations and suggestions}

Caregivers' concerns about the status of their patients when attending logo therapy sessions was a limitation of this study. In future studies, it is suggested, if possible, to run logo therapy sessions during the time other than patient's hemodialysis sessions. Alternatively, during logo therapy sessions, another person is suggested to take care of patients so that caregivers can attend the sessions with the least concern.

\section{Acknowledgments}

The authors would like to appreciate the authorities at the department of nursing, the Qazvin University of Medical Science, the personnel at the Bouali hospital for their cooperation in data collection, and also all the caregivers of hemodialysis patients who participated in this study. 
Authors' contribution

SZHG and ST were the main investigators who designed the study. SZHG led the team while ST and MHM collected the data and wrote the first draft. Moreover, MM analyzed data and LK collected the data and helped in writing the draft.

\section{Conflicts of interest}

The authors did not disclose any conflicts of interest.

\section{Ethical considerations}

Ethical issues (including plagiarism, data fabrication, double publication) have been completely observed by the authors.

\section{Funding/Support}

The Qazvin University of Medical Sciences supported the study.

\section{References}

1. Kanda H, Hirasaki Y, Iida T, Kanao-Kanda M, Toyama Y, Chiba T, et al. Perioperative management of patients with end-stage renal disease. J Cardiothorac Vasc Anesth. 2017;31(6):2251-67. doi: 10.1053/j.jvca.2017.04.019.

2. [Internet]. [cited 2016 Dec 29]. Available from: http://www. icdgroup.org/Content/Upload/pdf/salnama95.pdf.

3. Bayoumi MM. Subjective burden on family carers of hemodialysis patients. Open J Nephrol. 2014;4:79. doi: 10.4236/ojneph.2014.42011.

4. Ward JM, Getchell L, Garg AX; MyTEMP Investigators. Patient and caregiver involvement in a multicentre clustered hemodialysis trial. CMAJ. 2018;190:S32-3. doi: 10.1503/ cmaj.180403.

5. Verma S, Sayal A, Vijayan VK, Rizvi SM, Talwar A. Caregiver's burden in pulmonary arterial hypertension: a clinical review. J Exerc Rehabil. 2016;12:386-392. Published 2016;12:386-92. doi: 10.12965/jer.1632708.354

6. Pozet A, Lejeune C, Bonnet M, Dabakuyo S, Dion M, Fagnoni P, et al. Evaluation of efficacy and efficiency of a pragmatic intervention by a social worker to support informal caregivers of elderly patients (The ICE Study): study protocol for a randomized controlled trial. J Trials. 2016;17:531. doi: 10.1186/s13063-016-1622-8.

7. Sisek-Šprem M, Pahljina C, Herceg M, Mimica N, Petrović L, Radovanić B. Logotherapy as a psychotherapeutic technique in psychogeriatric palliative care wards. Socijalna Psihijatrija. 2019;47:344-350. doi: 10.24869/spsih.2019.344

8. Bastawrous M. Caregiver burden--a critical discussion. Int J Nurs Stud. 2013;50:431-441. doi: 10.1016/j. ijnurstu.2012.10.005.

9. Whitworth H, Whitworth J. A Caregiver's Guide to Lewy Body Dementia. New York : Demos Health; 2012.

10. Tretteteig S, Vatne S, Rokstad AM. The influence of day care centres designed for people with dementia on family caregivers - a qualitative study. BMC Geriatr. 2017;17:5. doi:10.1186/s12877-016-0403-2

11. Avsar U, Avsar UZ, Cansever Z, Yucel A, Cankaya E, Certez $\mathrm{H}$, et al. Caregiver burden, anxiety, depression, and sleep quality differences in caregivers of hemodialysis patients compared with renal transplant patients. Transplant Proc. 2015;47:1388-91. doi: 10.1016/j.transproceed.2015.04.054.

12. Costello SJ. The spirit of logotherapy. Religions. 2016;7:3. doi: 10.3390/rel7010003

13. Kusaba T, Sato K, Fukuma S, Yamada Y, Matsui Y, Matsuda S, Ando T, Sakushima K, Fukuhara S. Influence of family dynamics on burden among family caregivers in aging Japan. Fam Pract. 2016;33:466-70. doi: 10.1093/fampra/ cmw062.

14. Ulrichová M. Logo Therapy and Existential Analysis in Counselling Psychology as Prevention and Treatment of Burnout Syndrome. Procedia Soc Behav Sci. 2012;69:502-8. doi: 10.1016/j.sbspro.2012.11.439

15. Sri Suyanti T, Anna Keliat B, Catharina Daulima NH. Effect of logo-therapy, acceptance, commitment therapy, family psychoeducation on self-stigma, and depression on housewives living with HIV/AIDS. Enferm Clin. 2018;28 Suppl 1:98-101. doi: 10.1016/S1130-8621(18)30046-9.

16. Frankl VE. The will to meaning: Foundations and applications of logotherapy. New York : Plume, 2014.

17. Morgan JH. Late-life depression and the counseling agenda: exploring geriatric logotherapy as a treatment modality. Int J Psychol Res. 2011;6:94-101 doi:10.5195/hcs.2013.126

18. Schulenberg SE, Hutzell RR, Nassif C, Rogina JM. Logotherapy for clinical practice. Psychotherapy (Chic). 2008;45:447. doi: 10.1037/a0014331

19. Wong PT. From logotherapy to meaning-centered counseling and therapy. In: The human quest for meaning: Theories, research, and applications. Routledge: 2012;2:61947.

20. Guerra MP, Lencastre L, Silva E, Teixeira PM. Meaning in life in medical settings: A new measure correlating with psychological variables in disease. Cogent Psychol. 2017;4:1286747. doi: 10.1080/23311908.2017.1286747

21. Batthyány A. Logotherapy and Existential Analysis: Proceedings of the Viktor Frankl Institute Vienna. Springer; 2016.

22. Sun FK, Hung CM, Yao Y, Fu CF, Tsai PJ, Chiang CY. The Effects of logotherapy on distress, depression, and demoralization in breast cancer and gynecological cancer patients: a preliminary study. Cancer Nurs. 2019. doi:10.1097/ncc.0000000000000740.

23. Michalski K. Noogenic neuroses as suffering from senselessness of life in logotherapy and existential analysis by Viktor E. Frankl. Studies in the History of Philosophy. 2019;10(2):143-71. doi: 10.12775/szhf.2019.020

24. Cantekin I, Kavurmaci M, Tan M. An analysis of caregiver burden of patients with hemodialysis and peritoneal dialysis. Hemodial Int. 2016;20:94-7. doi: 10.1111/hdi.12311.

25. Alnazly EK. Burden and coping strategies among Jordanian caregivers of patients undergoing hemodialysis. Hemodial Int. 2016;20:84-93. doi: 10.1111/hdi.12318

26. Mobolaji-Olajide OM, Amira OC, Ademuyiwa IY, Arogundade FA, Duke E. The burden of caring for renal patients: The nurses perspective. Saudi J Kidney Dis Transpl. 2018;29:916-23. doi: 10.4103/1319-2442.239629.

27. Nagarathnam M, Reddy KP, Anuradha B, Sivakumar V, Latheef SAA. Assessment of burden among caregivers of hemodialysis patients at a tertiary care hospital of 
Andhra Pradesh. Indian J Nephrol. 2016;26:152-3. doi: 10.4103/0971-4065.172598.

28. Mollaoglu M, Kayatas M, Yurugen B. Effects on caregiver burden of education related to home care in patients undergoing hemodialysis. Hemodial Int. 2013;17:413-20. doi: 10.1111/hdi.12018.

29. Rioux JP, Narayanan R, Chan CT. Caregiver burden among nocturnal home hemodialysis patients. Hemodial Int. 2012;16:214-9. doi: 10.1111/j.1542-4758.2011.00657.x .

30. Jones L, Low J, Smith G, Burns A. The impact of end-stage kidney disease (ESKD) on close persons: a literature review. NDT Plus. 2008;1:67-79. doi: 10.1093/ndtplus/sfm046

31. Kang KA, Kim SJ, Song MK. CD program development applied logotherapy to improve quality of life of older school-age children with terminal cancer. Korean J Hosp Palliat Care. 2008;11:82-90.

32. Shin-Jeong K, Kyung-Ah K, Sun-Jeong P, Myung-Nam L, Young-Hee K. The effects of logotherapy on meaning of life of early adolescents with cancer. Asian Oncol Nurs. 2013 Mar 1;13(1). doi: 10.5388/aon.2013.13.1.49
33. James L. The effect of logotherapy on meaning and quality of life of the elderly in old age homes. Christ University; 2012.

34. Belasco AG, Sesso R. Burden and quality of life of caregivers for hemodialysis patients. Am J Kidney Dis. 2002;39:80512. doi: 10.1053/ajkd.2002.32001

35. Cohen LM, Germain MJ. Caregiver burden and hemodialysis. Clin J Am Soc Nephrol. 2014;9:840-2. doi: 10.2215/CJN.02690314.

36. Kang K, Im J, Kim H, Kim S, Song M, Sim S. The effect of logotherapy on the suffering, finding meaning, and spiritual well-being of adolescents with terminal cancer. 2009;15: 136-144. doi: 10.4094/jkachn.2009.15.2.136

37. Zecca C, Panicari L, Disanto G, Maino P, Singh A, Digesu GA, Gobbi C. Posterior tibial nerve stimulation in the management of lower urinary tract symptoms in patients with multiple sclerosis. Int Urogynecol J. 2016;27:521-7. doi: 10.1007/s00192-015-2814-6.

38. Frankl V. Man's Search for Meaning. Beacon Press; 2006.

Copyright $\odot 2020$ The Author(s); Published by Nickan Research Institute. This is an open-access article distributed under the terms of the Creative Commons Attribution License (http://creativecommons.org/licenses/by/4.0), which permits unrestricted use, distribution, and reproduction in any medium, provided the original work is properly cited. 